\title{
Strategies coping with labour stress from speech therapists in Greece
}

\author{
Maria Mpekou Theodoratou*1, Maria Plati ${ }^{1}$, Anastasia Tsouxli ${ }^{1}$, \\ Ourania Theodoridou ${ }^{1}$, Sofia Fotiadou ${ }^{2}$ and Vasilios Mpekos ${ }^{1}$
}

Address: ${ }^{1}$ A.T.E.I. Patras, Greece and ${ }^{2}$ Psychology, Greece

* Corresponding author

from International Society on Brain and Behaviour: 2nd International Congress on Brain and Behaviour

Thessaloniki, Greece. I7-20 November 2005

Published: 28 February 2006

Annals of General Psychiatry 2006, 5(SuppI I):SI 92 doi:I0.II86/I744-859X-5-SI-SI 92

\section{Background}

The aim of present research was to investigate the coping strategies that are used by speech therapists, in the effort to resolute a difficult situation or anything that causes the development of stress. More specifically, the study looked at whether speech therapists selected positive or negative coping strategies, and which strategies were most preferred.

\section{Materials and methods}

For our research we used the "scale of Toulouse" for the coping of problems. Questionnaires and interviews were administered to 86 speech therapists from Greece.

\section{Results}

Index focusing average: 31,58

Index sociable support: 31,40

Index control: 31,77

Index withdrawal: 18,74

Index change average: 27, 01

Index refusal: 23, 24

\section{Discussion}

According to the results from the statistical analysis, more important problems with the coping of stress are confronted by speech therapists of younger age, those that have less years of previous experience, those that don't work in metropolitan cities and those that work in the public sector. 